\title{
nature
}

\section{Seeds of consensus}

A global agreement on the terms of trade in genetically modified organisms is a victory for common sense. But it also reflects the pragmatic recognition that few would gain from a prolonged trade war over the issue.

$$
\mathrm{L}
$$

ast Saturday's agreement in Montreal of a Biosafety Protocol marks a welcome respite from the hostility that has character-ized international relations on the question of the risks and benefits of agricultural biotechnology (see page 473). The detail of the agreement leaves some key points unresolved. But at least it offers a framework for defusing potentially explosive tensions over the international movement of genetically modified (GM) organisms.

Two familiar armies arrived in Montreal to negotiate the agreement. The United States, along with the well-fed representatives of its biotechnology and farming industries, and a small number of food-exporting allies came to argue for minimal restrictions on the import and export of GM organisms. The European Union, a motley crew of environmental activists and most of the developing world came looking for a protocol that would echo their reluctance to accept the safety of such a trade. After last year's failures to agree a biosafety protocol at Cartagena, Colombia, or a format for discussing biotechnology at the World Trade Organization (WTO), the chances of agreement looked slim.

But, perhaps surprisingly, an agreement was struck. The Cartagena Protocol on Biosafety - so named to prevent any confusion with the Montreal Protocol on ozone depletion - sets out new conditions for transfer of live GM organisms between countries, allowing the importing country to make the decision.

The protocol was originally proposed almost a decade ago on the grounds that such transfers were seen as a threat (albeit a small one) to biodiversity. It became tougher to negotiate after environmentalists had successfully argued that it should cover not only live plants and seeds, but also imports of commodity grain, which, they said, could escape accidentally into the environment.
The new protocol sets fairly comprehensive controls on the movement of living organisms, as well as much narrower ones for grain. Shipments of GM grain will have to be labelled as such; but the labelling regime won't come into force until two years after the protocol does, which probably means 2003 or 2004. By then, the labelling issue will probably have been solved by market forces.

In defining the circumstances in which importing countries can decline to accept GM organisms, the protocol draws a fine balance. It rejects the need for "scientific certainty" in order for a party to make such a decision - a move being described by some environmentalists as a triumph for the precautionary principle which, they say, is espoused here for the first time in an international treaty. But the treaty also requires importers to use scientific risk assessment, including cost-benefit analysis, to lay grounds for exclusion.

On the face of it, allowing for labelling — even vague labelling, in three or four years' time - is a major concession by the United States and the agricultural biotechnology industry. This concession was surely made, in part, because of the knowledge that failure to reach any kind of agreement would augur very badly for international trade in GM organisms. But it was balanced by the protocol's own admission that it does not supersede parties' rights under the WTO. The WTO has enforcement mechanisms, where the new protocol has none.

The United States may recognize for now that bringing out the big stick — making a complaint to the WTO — on this issue would be counter-productive, turning Europe's teething troubles over GM food into a blanket rejection, with a trade war thrown in. Constructive engagement in the arcane art of scientific risk assessment is better than that.

\section{Electronic submissions now welcome}

\section{From this week, Nature encourages authors to send all manuscripts in one of a range of digital formats.}

W hatever the prophets may have said, the paperless office is nowhere in sight. But in Nature's offices, at least, the sheer quantity of accumulated paper is set to diminish progressively. For we are now able to receive electronic versions of manuscripts of submitted Articles and Letters from all disciplines, and to handle the documents through refereeing, discussion and editing, entirely electronically (we already accept electronic pre-submission enquiries.)

Many specialist journals have offered such a facility for some time. But since Nature is a general journal, the range of disciplines covered, with their respective and diverse established formats, has impeded its ability to open the electronic hatch to all comers, even though pilot experiments have been working successfully for several months.

No one should conclude that those submitting on paper will be discriminated against in any way. Nor will potential referees be excluded because they cannot handle a submission in electronic form. The publication process may prove slower on average for paper submissions, but only for the inescapable practical reasons that the
Internet is faster, more readily usable and more accessible by authors and referees than fax transmission, let alone the post.

Details of our online services for authors are gathered together in one virtual location: http://www.nature.com/submit (for a quick tour of what we can offer, see overleaf). Alternatively, simply e-mail nature@nature.com for instructions. Online submission is based on three stages: information via the Nature website; transmission via WAM!NET, a dedicated high-speed network providing reliable and secure file transfer using the Internet; and conversion to Adobe Portable Document Format (PDF) for assessment and refereeing.

Over the coming weeks, we will extend this facility to encompass Brief Communications. Over the months and years ahead, we expect burgeoning bandwidths to play their part in encouraging an increasing amount of electronic submission and refereeing. We expect, too, to be able to handle a greater variety of digital formats, both known and as yet unknown. Meanwhile, authors looking for the greatest speed of response from Nature are encouraged to use the new system. 